\title{
Analysing Gender Effect on the Speech Act of Suggestion: A Pilot Study
}

\author{
Mushtaq A. Sharqawi \\ Elizabeth M. Anthony \\ Centre for Language Studies, \\ Universiti Tun Hussein Onn Malaysia (UTHM), \\ Malaysia
}

DOI: https://doi.org/10.36941/ajis-2020-0o62

Abstract

This is a pilot study on analyzing the effect of gender on the speech act of suggestion. It introduces preliminary analyses of whether gender affects the use of suggestion strategies produced and recognized by Iraqi EFL learners. The strategies are dealt with from three perspectives: structural, directness, and politeness. The purpose of this small-scale study is twofold, (1) to explore if there is a relationship between gender and suggestions and (2) to check the validity and reliability and thus the workability of the instruments in question to a large-scale study. To this end, the study sampled voluntarily, on an equal base, 10 male and 10 female fourth-year undergraduates using a name-in-box method. The study used two quantitative-based instruments to elicit suggestions: Written Discourse Completion Task (WDCT) and Multiple-choice Discourse Completion Task (MDCT). Each of which consisted of 12 situations approximating real-like interactions. The corpus was statistically analyzed via SPSS and yielded that gender affected the use of structural and directness strategies of suggestions, but it had no effect on the politeness strategies. Results along with the feedback of the raters, who were chosen to rate the situations, have both proven that the instruments in question are valid and reliable to work on relevant further studies.

Keywords: Suggestion; gender effect; raters' responses; pilot study; politeness

\section{Introduction}

Speech acts are the ultimate ends that EFL learners need to attain in order to be able to express themselves in a native-like manner. While speaking, speakers inevitably employ numerous types of speech acts such as requesting, commanding, agreeing, disagreeing, thanking, suggesting etc. In communication, it is the speech act that shapes what is intended to convey (Leech, 2016) and here rises the need for speech acts in the EFL context.

The speech act of suggestion is one of these acts which are made to the advantage of the hearer (Al-aadeli, 2014). In other words, suggestions are types of propositions or plans dedicated to helping others. But from a pragmatic perspective, suggestions are indexed under the category of facethreatening acts since humans, by their nature, do not want to be proposed what to do (Edstrom, 20o8). This means, according to Brown \& Levinson (1987), there are certain polite and impolite ways that one needs to be careful about when making suggestions. 


\section{Literature Review}

Much work has been done in the field of pragmatics from a broader perspective but when narrowing down the review to the speech act literature in eastern and western EFL contexts, numerous issues have been found out. One of them is that speech acts studies in eastern EFL context, according to (Pishghadam \& Sharafadini, 2011; Sharqawi \& Anthony, 2019a) have been ignored as compared to the structure of language. But the ways speech acts are expressed (pragmatic knowledge) vary depending on the EFL learners' knowledge of the structure of that act (linguistic knowledge) and how appropriately the act in question is employed (sociolinguistic knowledge). This means that the speech act of suggestion is one of these acts which learners have to pay attention to. Scholars like Jiang (2006) and Petrey (2016) confirm that the speech act of suggestion has been sidelined in EFL settings. Such a paucity calls for primary studies and thus the researcher aims to set his study on this act. Another issue in the recent literature was the lack of gender studies when compared with nongender ones (Moradi, 2017; Sharqawi \& Anthony, 2019a). In response to this lack, the researcher considers gender involvement in the population selection criteria. The involvement of gender in the speech act of suggestion may reveal significant variations as gender has been acknowledged by linguists that, at almost every level of language, gender seems to have an impact on the way language is uttered and or perceived (Ehrlich, Meyerhoff, \& Holmes, 2017). Moreover, suggestion is expected to vary in terms of gender since suggestion according to Martínez-flor (2005), Al-aadeli (2014), Sharqawi \& Anthony (2019b), and Sharqawi \& Anthony (2020a) is a face-threatening act. This means that learners should attain certain politeness strategies when using suggestions. Examples of gender variations in studies dealing with face-threatening acts are frequent such as refusals by Abed (2011) and Arani \& Tehrani (2013), complaints by Devici (2015), apologies by Elham (2017) and Keshani \& Heidari-Shahreza (2017), disagreements by Heidari, Rasekh \& Simin (2014), AL-Khanaifsawy (2014), Taqim (2016) and Sharqawi \& Anthony (2019c). Since the politeness level of any speech act depends on the level of the directness of that act (Leech, 2016), then it is logical to assume that gender affects the directness level too.

Not only at the politeness and directness level, but the syntactic structures of speech acts are expected to vary with gender (Sharqawi \& Anthony, 2020b). In this sense Coates (2015) claims that men and women have unequal access to language structures as women tend to show better manageability in (and employing more) structures than men in general. The latter claim is supported by Edstrom (2004) in that women are superior in language acquisition and use. In other words, women are linguistically more competent than men.

\section{Rationales for the Study}

The purpose of this study, being a pilot, is to assess the feasibility of the WDCT and MDCT. Although it is a mini version of the full-scale study involving a smaller number of participants, however, all WDCT and MDCT situations were used in order to discover potential issues concerning the clarity of language to the part of the EFL learners, their closeness to real-like interactions, and their reflectivity of social values (social status and distance). The study also aims at proving the internal validity of the two instruments since it checks whether the instruments are valid to measure what they are supposed to measure, i.e., suggestions. Another rationale for the study is to check the face validity of the instruments. Face validity, according to Kassem (2018) is concerned with how the instruments seem to be correct to the participants and other researchers. This has been accomplished by choosing four raters, two professors majoring in teaching English linguistics and two lecturers of linguistics. Their duty was to rate every situation in the WDCT and MDCT individually using a five-level Likert scale ranging from 'strongly agree' to 'strongly disagree'.

The main purpose of this study, being pilot, is not exploratory in terms of linguistic content, i.e., it is not meant to prove or disprove hypotheses (Lancaster, Dodd \& Williamson, 2004; Given, 2008) relative to suggestion and gender but rather to provide an insight into how to design a research 
protocol. Due to its limited number of participants, the current study can only give preliminary outcomes about the speech act of suggestion and this means that its findings cannot be generalized over the whole population. The study is, however, exploratory of procedural issues which may not have foreseen prior to the conduction of the large-scale study.

Although pilot studies are not mainly set to prove or disprove hypotheses (Lancaster, Dodd \& Williamson, 2004; Given, 2008), but rather are set to check if the hypotheses under study are capable of being tested in the large-scale study, however, pilot studies have to provide some linguistic outcomes in order to "provide sufficient assurance to enable a larger definitive trial to be undertaken" (Lee et al., 2014: 1). Thus, to check the feasibility and the workability of this mini-scale study to the larger one, the researcher proposed three basic hypotheses.

1. a. $\mathrm{H}_{1}$. There is a relationship between gender and the structural strategies of suggestion.

b. $\mathrm{H}_{\mathrm{o}}$. There is no relationship between gender and the structural strategies of suggestion.

2. a. $\mathrm{H}_{1}$. There is a relationship between gender and the directness strategies of suggestion.

b. $\mathrm{H}_{\mathrm{o}}$. There is no relationship between gender and the directness strategies of suggestion.

3. a. $\mathrm{H}_{1}$. There is a relationship between gender and the politeness strategies of suggestion.

b. $\mathrm{H}_{\mathrm{o}}$. There is no relationship between gender and the politeness strategies of suggestion.

\section{Methodology}

The study examined the production and recognition of suggestions at three linguistic perspectives; structure, directness and politeness. A quantitative method has been set because the full-scale study is quantitative too. In line with Creswell (2012), to reduce the bias in selecting the participants, the study adopted a probabilistic random sampling in which names-in-a-box method was applied. A total of 20 Iraqi EFL learners were chosen for the study, all of whom were fourth-year students of the English Language Department at the Education College at the University of Qadisiyah. Being a gender study, equally 10 male and 10 female participants were selected to attend the WDCT and MDCT.

\subsection{Instrumentation and Models}

The instrument of data collection consisted of two instruments called tasks: WDCT and MDCT preceded by a demographic information part in which the participants had to identify their gender, nationality, native language, and age.

The WDCT consisted of 12 open-ended situations involving a conversational-like scenario between a hypothetical classmate and an actual participant. All the situations were limited to university settings. Each situation was contextualized to require a suggestion as a response. The WDCT was designed to elicit the strategies of suggestion in terms of structure and directness. Although social status and distance were not indicated in the WDCT, however, every situation carried a different degree of urgency in order to motivate the participants to respond variously. All the situations were written to have a clear and simple language as possible so that participants can easily understand the situations.

Suggestions elicited from the WDCT were analyzed in terms of two perspectives: (1) the structural strategies of suggestions which are divided into 12 types as Table 1 shows. This model is inclusive of all possible structures of suggestions which native and non-native speakers produce (Jiang, 2006). It is a modified version of the original model by Martinez-Flor (2005). 
Table 1: Suggestions from a structural perspective

\begin{tabular}{|l|l|l|l|} 
& Structural Strategies & Example & Directness Strategies \\
\hline $\mathbf{1}$ & Suggestion with performative verbs & 'I suggest...' or 'I propose', etc. & Direct \\
suggestions
\end{tabular}

(2) the directness strategies of suggestion following the model of Martinez-Flor (2005) which has three types of strategies. First, 'direct suggestions' which are realized by suggestions 1,2,3, and 4 in Table 1. Second, 'conventionalized indirect suggestions' which are realized by suggestions 5, 6, 7, 8, 9, and 10. Third, 'indirect suggestions' which are realized by suggestions 11 and 12 .

On the other hand, the MDCT consisted of 12 close-ended triple-choice situations. The MDCT was used to elicit the learners' recognition of the politeness strategies of suggestions. (3) The politeness model is taken with modifications from Brown and Levinson (1987) politeness model combined with Li's (2010) redressive acts. The redressive acts include these mitigators: 'OK?', 'right?', 'maybe', 'perhaps', 'I think', and 'you know'. The model of politeness branches into three suggestions: (a) 'bald on-record suggestions' realized by the direct suggestions, (b) 'on-record suggestions' realized by the conventionalized indirect suggestions or direct suggestions plus redressive acts, and (c) 'offrecord suggestions' realized by the indirect suggestions. Each situation has a hypothetical scenario in which the social status ' $\mathrm{S}$ ' and distance ' $\mathrm{D}$ ' are both considered. Every two situations in the MDCT have one of the following scenarios as Table 2 indicates.

Table 2: MDCT social scenarios

\begin{tabular}{|c|c|c|}
\hline & Situations & Social Scenario \\
\hline 1 & $1 \& 2$ & {$[$ between $=\mathrm{S}]+\mathrm{D}$} \\
\hline 2 & $3 \& 4$ & {$[$ from $-\mathrm{S}$ to $+\mathrm{S}]+\mathrm{D}$} \\
\hline 3 & $5 \& 6$ & {$[$ from $+\mathrm{S}$ to $-\mathrm{S}]+\mathrm{D}$} \\
\hline 4 & $7 \& 8$ & {$[$ from $-\mathrm{S}$ to $+\mathrm{S}]-\mathrm{D}$} \\
\hline 5 & $9 \& 10$ & {$[$ between $=\mathrm{S}]-\mathrm{D}$} \\
\hline 6 & $11 \& 12$ & [from $+\mathrm{S}$ to $-\mathrm{S}]-\mathrm{D}$ \\
\hline
\end{tabular}

Where $=$ means equal, $+\mathrm{S}$ means higher status, $-\mathrm{S}$ means lower status, $+\mathrm{D}$ means distance, $-\mathrm{D}$ means no distance

The reason for including these values is to measure how the participants recognize suggestions appropriately by selecting one of the three existing suggestions. Each situation contained three suggestions as choices and the participants had to select only one suggestion: Bald on-record, onrecord, or off-record suggestion. It is important to mention that choosing the bald-on record suggestion is not always considered 'impolite' because if it is used, for instance, between close friends it is then 'fair'. Thus, in the analysis, the coding scheme of politeness explained in the following table comprises a scale ranging from 'rude' to 'very polite' suggestion depending on the social scenario and the type of suggestion as explained below. 
Table 3: The social scenarios and coding scheme

\begin{tabular}{|c|c|c|c|c|}
\hline Situation & Social Scenario & 'bald-on record' suggestion & 'on-record' suggestion & 'off-record' suggestion \\
\hline $1 \& 2$ & [between $=$ S] $+\mathrm{D}$ & 'impolite' & 'fair' & 'polite' \\
\hline $3 \& 4$ & {$[$ from $-\mathrm{S}$ to $+\mathrm{S}]+\mathrm{D}$} & 'rude' & 'fair' & 'polite' \\
\hline $5 \& 6$ & {$[$ from $+\mathrm{S}$ to $-\mathrm{S}]+\mathrm{D}$} & 'impolite' \\
\hline $7 \& 8$ & {$[$ from $-\mathrm{S}$ to $+\mathrm{S}]-\mathrm{D}$} & 'Impolite' & 'fair' & 'polite' \\
\hline $9 \& 10$ & {$[$ between $=\mathrm{S}]-\mathrm{D}$} & 'fair' & 'polite' & 'very polite' \\
\hline $11 \& 12$ & {$[$ from $+\mathrm{S}$ to $-\mathrm{S}]-\mathrm{D}$} & 'fair' & 'polite' & 'very polite' \\
\hline
\end{tabular}

Thus, for instance, depending on the social scenario in situation 1 and 2, when a participant chooses a bald-on record suggestion (the first choice), the suggestion is then considered 'impolite', when choosing on-record (the second choice), it is considered 'fair', and when choosing off-record (the third choice), it is considered 'polite'. This process is automatically run by an Excel sheet that was conditionally formatted, by the researcher, to determine the type of suggestions with colours.

\subsection{Scoring}

The total number of the situations of the two DCTs is 24 (12 in the WDCT and 12 in MDCT). To score, each situation was assigned one mark. So, the participant who answered all the 24 situations got the full mark, i.e., 24. This means 12 marks to be the minimum mark and therefore scoring less than 12 marks was deemed failed. It is important to exclude the failed results because those who scored less than 12 marks were regarded as unserious to perform the DCTs and therefore their results may contaminate the valid results during the course of analysis.

\subsection{Procedures}

After getting the lecturer's consent form signed by the head of the department, the learners were asked to voluntarily participate in the study. Almost everyone was pleased to join the tasks and it was their first experience. The names-in-a-box method was applied to choose ten male and ten female participants. Informed consent forms were distributed to them and were instructed to read the forms carefully before they sign. Furthermore, the researcher explained the content of the form in detail in case someone missed or misunderstood something. After collecting the signed forms, the DCT sheets were distributed to the participants and were given detailed instructions on how to respond.

\subsection{Rating DCTs}

Four raters were chosen to rate the WDCT and MDCT situations in order to get the raters' views and thus to attain face validity. The raters were given special DCT sheets similar to the ones given to the participants. The raters had to tick $\checkmark$ to choose one value out of five scales assigned to every single situation. When done, their choices were analysed statistically for Cronbach's Alpha in addition to the raters' feedback. Here is the rating table assigned to the WDCT situations.

Table 4: WDCT rating table

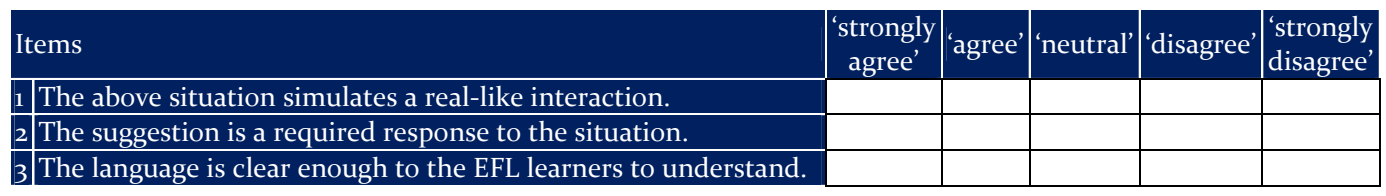


To assess the face validity of the MDCT situations, the raters were asked to rate each situation individually using the following table.

Table 5: MDCT rating table

\begin{tabular}{|c|c|c|c|c|c|}
\hline Items & $\begin{array}{l}\text { 'strongly } \\
\text { agree'' }\end{array}$ & 'agree' & 'neutral' & 'disagree' & $\begin{array}{l}\text { 'strongly } \\
\text { disagree' }\end{array}$ \\
\hline \begin{tabular}{|l|l}
1 & The above situation simulates a real-like interaction.
\end{tabular} & & & & & \\
\hline 2 The suggestion is a required response to the situation. & & & & & \\
\hline \begin{tabular}{|l|l}
3 & The language is clear enough to the EFL learners to understand. \\
\end{tabular} & & & & & \\
\hline 4 Social status and distance are indicated in the situation. & & & & & \\
\hline
\end{tabular}

Likewise, as in the case of the WDCT, the raters' responses are thus analysed accordingly for face validity. It is noticeable that Table 5 resembles Table 4 except for item 4 where the social status and distance are included for rating. Additional comments by the raters were assigned a space under every situation. Results of the raters' responses are presented in the next section

\section{Results and Discussions}

In this section, data are analysed and discussed in three directions: (1) The linguistic content where the independent variable of gender affects the dependent variables (suggestion strategies), (2) the raters' response to each situation of the DCTs, and finally (3) the procedural issues and the potential gaps in the DCTs form which appeared on the surface during the conduction of this study.

\subsection{Results Based on Linguistic Analysis \\ 5.1.1 Demographic Information}

Analysing the participants' demographic information, it was found that all the participants have responded to every required item, i.e., no items were left unchecked except for the language proficiency level which was done by the researcher depending on the students' documented averages obtained from their certificates of the last year. Regarding their nationality and native language, all the participants were Iraqi nationals with Arabic tongue.

Regarding the participants' age, 9 of the male were 'below 22 years old' and one was '22-25 years old' while 5 of the female were 'below 22 years old' and the other 5 were '22-25 years old'. The following figure illustrates the percentages.

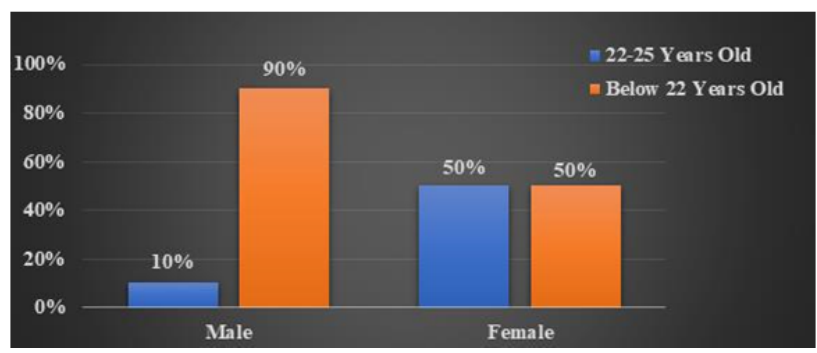

Figure 1: Male and female ages

The demographic part also questioned the participants' English language proficiency level by presenting a scale of five levels starting from 'very poor' to 'very good'. In terms of gender, 9 of the male were 'good' and one was 'very good'. For the female, 7 were 'good' while the rest 3 were 'fair' as the following figure depicts. 


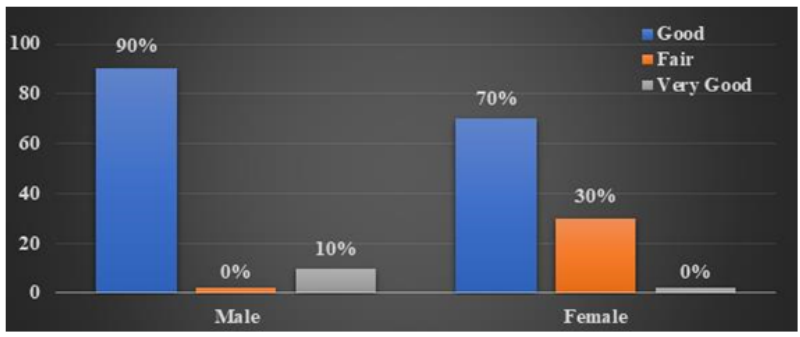

Figure 2: Male and female English language proficiency level.

\subsubsection{Hypotheses Testing}

The number of the WDCT situations is 12 and the number of the participants (the male and female) is 20 , so the whole number of the situations is $12 \mathrm{X} 20=240$ valid and invalid situations. 120 situations by the male plus 120 by the female. The total number of the valid situations is 210 and the invalid is 30. Below is the distribution of the responses.

Table 6: Gender responses.

\begin{tabular}{|c|l|c|c|}
\hline & Responses & Frequency & Percentage \\
\hline 1 & Male valid responses & 98 & $40.83 \%$ \\
\hline 2 & Male invalid responses & $\mathbf{2 2}$ & $9.16 \%$ \\
\hline 3 & Female valid responses & 112 & $46.66 \%$ \\
\hline 4 & Female invalid responses & 8 & $3.33 \%$ \\
\hline
\end{tabular}

In total, the number of valid situations is 120 and the invalid 30 . It is clear that the female performed better than the male in the WDCT. In general, although, $90 \%$ of male language proficiency level was 'good' against $70 \%$ of female as 'good' too as shown in figure 2 , however, female performance in the WDCT was better. Besides, 7 of the female have accomplished the full mark (i.e, 24) while only one male scored 24. These results go in line with Edstrom (2004) claiming those females are linguistically more capable than male.

In terms of the structural strategies of suggestions and since the male valid situations are less than the female ones, then it is expected in advance that the male will not employ as many strategies as the female.

Table 7: Distribution of structural strategies.

\begin{tabular}{|c|c|c|c|c|c|c|}
\hline & \multirow{2}{*}{ Structural Strategy } & \multicolumn{2}{|c|}{ Male } & \multicolumn{2}{|c|}{ Female } & \multirow{2}{*}{$\begin{array}{l}\text { Total } \\
\text { Perc. }\end{array}$} \\
\hline & & Freq. & Perc. & Freq. & Perc. & \\
\hline 1 & performative verbs & 41 & $41.8 \%$ & 20 & $17.8 \%$ & $59.6 \%$ \\
\hline 2 & Nouns & 8 & $8.1 \%$ & 6 & $5 \cdot 3 \%$ & $13.4 \%$ \\
\hline 3 & Imperatives & 9 & $9.1 \%$ & 22 & $19.6 \%$ & $28.7 \%$ \\
\hline 4 & negative imperatives & o & $\mathrm{o} \%$ & 4 & $3 \cdot 5 \%$ & $3 \cdot 5 \%$ \\
\hline 5 & interrogative structures & 5 & $5.1 \%$ & 9 & $8 \%$ & $13.1 \%$ \\
\hline 6 & 'let's' & 3 & $3 \%$ & 1 & $0.8 \%$ & $3.8 \%$ \\
\hline 7 & verb 'need' & o & $0.0 \%$ & 5 & $4.4 \%$ & $4.4 \%$ \\
\hline 8 & possibility or probability & 5 & $5.1 \%$ & 6 & $5 \cdot 3 \%$ & $10.4 \%$ \\
\hline 9 & 'should', 'would' and 'had better' & 24 & $24.4 \%$ & 20 & $17.8 \%$ & $42.2 \%$ \\
\hline 10 & Conditions & $\mathrm{o}$ & $\mathrm{o} \%$ & 2 & $1.7 \%$ & $1.7 \%$ \\
\hline 11 & impersonal forms & 3 & $3 \%$ & 15 & $13.3 \%$ & $16.3 \%$ \\
\hline 12 & Hints & o & $\mathrm{o} \%$ & 2 & $1.7 \%$ & $1.7 \%$ \\
\hline To & & 98 & $100 \%$ & 112 & $100 \%$ & $200 \%$ \\
\hline
\end{tabular}

Where freq. means frequency, perc. means percentage 
The table shows four types of strategies which have never been employed by the male. These were 'negative imperative strategy', 'verb need', 'condition', and 'hint'. Although these strategies were exclusive to the female, however, the female have employed them with lower frequencies as indicated. The most frequent strategies by the male were:

1) 'Performative verbs' namely 'I suggest...' and 'I propose...'

2) 'should, would and had better' namely 'You should...'.

Regarding the female, the common strategies were:

1) 'Imperatives'; 'Try to ...',

2) 'performative verbs'; 'I suggest...', and

3) 'should, would and had better'; 'You should...' and 'You had better...'.

Arguing from these female-exclusive strategies and regardless of the total number of the male strategies (98) compared to the female (112), and depending on percentages, it is possible to claim that the female have produced a higher number of strategies than the male. To know whether the relationship between gender and the use of the structural strategies of suggestion was due to a chance or not, a statistical test called Chi-square test of independence was needed for this purpose.

Table 8: Chi-square values in terms of structural strategies

\begin{tabular}{|l|c|c|c|}
\hline \multirow{2}{*}{ Pearson Chi-Square } & Value & $\mathrm{df}$ & Asymp. Sig. (2-sided) \\
\cline { 2 - 4 } & $35 \cdot 790^{\mathrm{a}}$ & 11 & 0.00 \\
\hline
\end{tabular}

Statistically, since the test states that the 'Asymp. Sig.' (the P-value) is o.oo and it is $<0.05$ (Alpha level), then we can reject $1 . \mathrm{H}_{\mathrm{o}}$ and this entails that $1 . \mathrm{H}_{1}$ is proven true. This means that there is a significant relationship between gender and the use of these strategies.

Regarding the directness strategies of suggestion, the researcher followed the same procedures to explain their relevance to gender if any. There are three directness strategies of suggestion: Direct, conventionalized indirect, and indirect. The table below shows gender directness variations with percentages.

Table 9: Distribution of directness strategies

\begin{tabular}{|c|c|c|c|c|c|c|}
\hline \multirow{2}{*}{ Directness } & \multicolumn{2}{|c|}{ Male } & \multicolumn{2}{|c|}{ Female } & \multirow{2}{*}{$\begin{array}{l}\text { Total } \\
\text { Freq. }\end{array}$} & \multirow{2}{*}{$\begin{array}{l}\text { Total } \\
\text { Perc. }\end{array}$} \\
\hline & Freq. & Perc. & Freq. & Perc. & & \\
\hline Direct & 58 & $59.1 \%$ & 52 & $46.4 \%$ & 110 & $105.5 \%$ \\
\hline Conventionalised indirect & 37 & $37 \cdot 7 \%$ & 43 & $38.3 \%$ & 80 & $76 \%$ \\
\hline Indirect & 3 & $3 \%$ & 17 & $15.1 \%$ & 20 & $18.1 \%$ \\
\hline Total & 98 & $100 \%$ & 112 & $100 \%$ & 210 & $200 \%$ \\
\hline
\end{tabular}

Because the male differed from the female in the total number of strategies; 98 opposed to 112, so it is practical to rely on the percentages rather than the frequencies. Following the difference in percentages, it is clear that the male direct strategies were more than the female. Regarding indirect strategies, the female were found to produce more. The female common strategy was impersonal form'; 'It would be better...'. To know if there is a significant relationship between gender and the directness strategies of suggestion, there has to be a statistical clue and thus Chi-square test was used in this regard.

Table 10: Chi-square values in terms of directness strategies

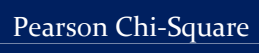

\begin{tabular}{c|c|c|} 
Value & df & Asymp. Sig. (2-sided) \\
\hline $9.687^{\mathrm{a}}$ & 2 & 0.008 \\
\hline
\end{tabular}


The above excerpt from SPSS reveals that the P-value $0.008<0.05$. This statistically indicates that we can reject $2 . \mathrm{H}_{0}$. Thus, $2 . \mathrm{H}_{1}$ is true. As a result, a significant relationship between the directness of suggestions and gender is found. As seen in the above table, the P-value in this test is higher than the $\mathrm{P}$-value of the former test. This difference was due to the fact that the male conventionalised indirect strategies resembled the female ones and this resemblance affects the level of significance in the second Chi-square test. Since the male resembled the female in the percentage of the conventionalised indirect strategies, so gender differences exhibited only at the direct and indirect levels. After proving the effect of gender on directness, it is now clear that the male use more direct suggestions than the female. On the other hand, the female use more indirect suggestions than the male.

Finished with analysing the results of the WDCT, now it is the turn to analyse the results of the MDCT. Of the politeness strategies of suggestion, the results were analysed based on the politeness coding shown earlier in Table 3. It is worth mentioning that, unlike the case with WDCT, all the situations in the MDCT were responded to. This means that the learners did better in the MDCT than in the WDCT. Perhaps this is due to the nature of the MDCT where the participants have only to select the answer rather than writing it as with the WDCT.

Table 11: Gender distribution of politeness strategies

\begin{tabular}{|c|c|c|c|c|c|c|c|}
\hline \multirow{2}{*}{\multicolumn{2}{|c|}{ Scale }} & \multicolumn{2}{|c|}{ Male } & \multicolumn{2}{|c|}{ Female } & \multirow{2}{*}{$\begin{array}{l}\text { Total } \\
\text { Freq. }\end{array}$} & \multirow{2}{*}{$\begin{array}{l}\text { Total } \\
\text { Perc. }\end{array}$} \\
\hline & & \multirow{2}{*}{$\begin{array}{c}\text { Freq. } \\
3\end{array}$} & \multirow{2}{*}{$\begin{array}{l}\text { Perc. } \\
2.5 \%\end{array}$} & \multirow{2}{*}{$\begin{array}{c}\text { Freq. } \\
4\end{array}$} & \multirow{2}{*}{$\begin{array}{l}\text { Perc. } \\
3.3 \%\end{array}$} & & \\
\hline 1 & Rude & & & & & 7 & $5.8 \%$ \\
\hline 2 & Impolite & 16 & $13.3 \%$ & 13 & $10.8 \%$ & 29 & $24.1 \%$ \\
\hline 3 & Fair & 38 & $31.6 \%$ & 35 & $29.1 \%$ & 73 & $60.7 \%$ \\
\hline 4 & Polite & 44 & $36.6 \%$ & 48 & $40 \%$ & 92 & $76.6 \%$ \\
\hline 5 & Very polite & 19 & $15.8 \%$ & 20 & $16.6 \%$ & 39 & $32.4 \%$ \\
\hline \multicolumn{2}{|c|}{ Total } & 120 & $100 \%$ & 120 & $100 \%$ & 240 & $200 \%$ \\
\hline
\end{tabular}

As the table reveals, it is clear that both genders approached each other with a high degree of consistent resemblance in the number of 'bold on-record', 'on-record', and 'off-record' suggestions. It seems they both employed nearly matching numbers of these strategies on each scale. Although the differences remained low, however, the above table shows, in terms of gender, that the most frequent strategy was 'polite' and the lowest was 'impolite' By looking at the percentages, it can straightforwardly be concluded that more than half of the male and female strategies were 'polite'. This means that both genders were polite in their suggestions. The numbers are visualized in the underneath figure.

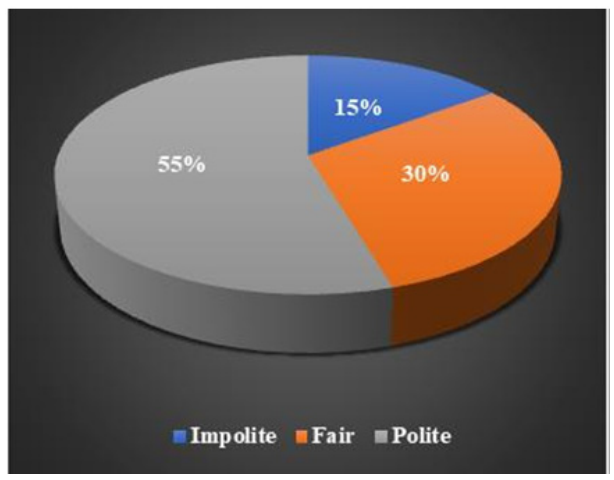

Figure 3: Gender percentages of politeness strategies. 
To check if there is a significant relationship between gender and the politeness strategies, a Chisquare test was performed and resulted in the following.

Table 12: Chi-square values in terms of politeness strategies

\section{Pearson Chi-Square}

\begin{tabular}{|c|c|c|}
\hline Value & $\mathrm{df}$ & Asymp. Sig. (2-sided) \\
\hline $.425^{\mathrm{a}}$ & 2 & 0.808 \\
\hline
\end{tabular}

The P-value $0.808>0.05$ meaning we cannot reject the $3 . \mathrm{H}_{\mathrm{o}}$ and thus $3 . \mathrm{H}_{1}$ is then untrue. This necessitates no significant relationship between gender and the politeness strategies. To sum up, the above discussions whether these gender similar performances were due to a chance or not, it is now reasonable to claim, out of their high percentages of polite strategies, that both genders were significantly polite.

\subsection{Results Based on the Raters' Responses}

Four raters were chosen by the researcher to validate the DCTs, two linguistic professors and two lecturers of linguistics. They were given special forms in which every single situation was assigned a rating table. See Table 4. On the other hand, every situation in the MDCT was assigned a different rating table. See Table 5 . Doing so contributes to the face validity of the two DCTs in addition to consulting their feedback and comments about the potential issues existed in the situations. The researchers collected and analysed the raters' responses statistically to obtain Cronbach's Alpha as a way to measure the face validity. Hence, Table 13 presents the Alpha values of each WDCT situation and their total.

Table 13: Cronbach's Alpha of WDCT situations.

\begin{tabular}{|c|c|}
\hline Situation & Cronbach's Alpha \\
\hline 1 & 0.750 \\
\hline 2 & 0.686 \\
\hline 3 & 0.750 \\
\hline 4 & 0.698 \\
\hline 5 & 0.625 \\
\hline 6 & 0.712 \\
\hline 7 & 0.857 \\
\hline 8 & 0.915 \\
\hline 9 & 0.771 \\
\hline 10 & 0.824 \\
\hline 11 & 0.610 \\
\hline 12 & 0.761 \\
\hline Total & 0.964 \\
\hline
\end{tabular}

It is shown that all the values are more than 0.5 (which is a low level in social sciences). This indicates a good level of acceptability. Regarding the face validity of the MDCT situations, Table 14 presents the related values.

Table 14: Cronbach's Alpha of MDCT situations.

\begin{tabular}{|c|c|}
\hline Situation & Cronbach's Alpha \\
\hline 1 & 0.838 \\
\hline 2 & 0.941 \\
\hline 3 & 0.667 \\
\hline
\end{tabular}




\begin{tabular}{|c|c|}
\hline Situation & Cronbach's Alpha \\
\hline 4 & 0.815 \\
\hline 5 & 0.702 \\
\hline 6 & 0.932 \\
\hline 7 & 0.872 \\
\hline 8 & 0.889 \\
\hline 9 & 0.686 \\
\hline 10 & 0.889 \\
\hline 11 & 0.796 \\
\hline 12 & 0.859 \\
\hline Total & 0.942 \\
\hline
\end{tabular}

Again, the values remained above 0.5. It is worth mentioning that the Cronbach's Alpha with 0.6 is considered acceptable in social sciences but in pure sciences, in most cases, is treated as low or unacceptable. Out of these statistical numbers, it is now permissible to claim that both WDCT and MDCT have met the requirement of face validity. Both tasks, from the raters' perspective, seem to be valid and workable to the full-scale study. Other details on reliability and validity are discussed in the subsequent section.

\subsection{Results Based on Procedural Issues}

As for the WDCT situations, the participants' responses were suitable to the context of the situations. Although there were 30 unanswered situations in total, however, this number is low when compared to the number of the answered situations that is 210 out of 240 in total.

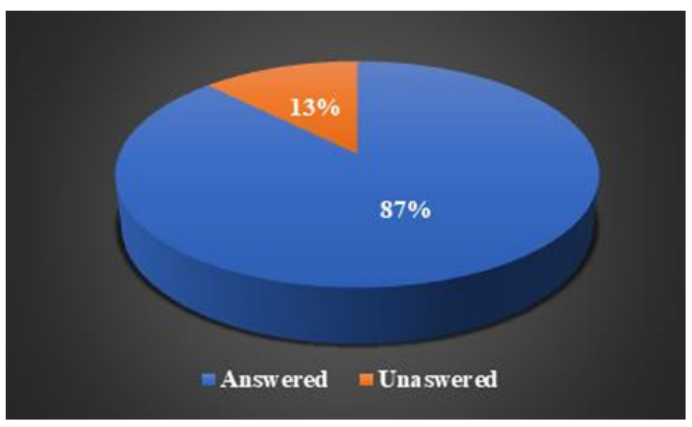

Figure 4: Percentages of the answered and unanswered situations.

Having such a high percentage of the answered situations reflects how well the situations fit to the study. The researcher, in addition to the supervisor's feedback, has consulted two linguistics professors during the process of modifying the WDCT and MDCT. This percentage also reflects that the participants have understood the context of the WDCT situations. It is normal that some situations were left answered since the WDCT is an open-ended task that requires writing that is according to Myles (2002) is an energetically effortful task, and thus participants may not feel selfencouraged to answer them all. Dissimilar to the WDCT, the participants responded to the MDCT in full, i.e., all the participants have scored full marks in this part of the task. It is because the task is close-ended and the participants had only to tick (the choices) suggestions which are ready-made for them. Such a task is easier and faster for the participants than the WDCT since the latter demands writing their suggestions.

In terms of the nature of the WDCT responses, two of the ten females made lengthy and redundant suggestions. One female wrote a justification with the suggestion as a technique to 
convince the hearer to take the suggestion. Below are two samples.

"You damage files if you remove the flash drive immediately without performing the electronic removal so I think you should perform the electronic removal". (Situation 5).

"I don't know of the game. I don't play the game so I'm not familiar with it. I suggest that you tell Ali. I'm sure he knows a lot about this game on the mobile". (Situation 8).

As a remedy, the researchers will take this issue into account in the actual study by informing the participants to write as short suggestions as possible. They will also be informed not to support their suggestions with lengthy justifications. One more issue was that one response was a warning and one command, not suggestions. Here are two samples.

"Don't go to the periodicals room! Go to another place!" (Situation 12).

"Stop now and come back tomorrow!" (Situation 6).

An issue related to the social tradition appeared. The society of the city of Diwaniyah, where Qadisiyah University is located, is a Muslim conservative where the female privacy has to be carefully considered. In this respect, although the ten female participants agreed to be photographed during the conduction of the tasks after being assured that their anonymity of pictures would be preserved by the researcher, however, their condition was that the pictures could be taken from the backside so their faces would not appear in the picture.

In the conduction of the tasks, the researcher read the situations, translated them into Arabic, and instructed the participants to respond to the two tasks. But it was noticed that two male participants started responding to the MDCT first. This could result in the participants copy some structures form the MDCT situations and write them in the WDCT. To avoid such contamination that may occur in the actual study, the researcher decided to instruct the participants to start with the WDCT first and then when finished they can do the MDCT.

\section{Reliability and Validity}

According to Heaton (1988) and Carr (2011), an instrument is reliable when it enables the researcher to measure what it was designed to measure and thus, in the current study, reliability was achieved because the WDCT has successfully elicited suggestions in terms of structural and directness strategies and the MDCT has successfully tested the participants' politeness strategies.

According to Neuendorf (2016), a study has to accomplish the three types of validities; face, content, and construct validity. Face validity has been discussed in the above section where raters' feedbacks have been taken into considerations, besides the prior guidance by the supervisor and other two linguistic professors whose suggestions contributed a lot to the development of the two DCTs. Content validity is concerned with how suitable the instrument is set to elicit certain linguistic aspects rather than others (Neuendorf, 2016; Yuksel \& Inan-Karagul, 2018). To this standard, the two DCTs have been set to elicit the speech act of suggestion rather than other speech acts. Having $87 \%$ responses out of 240 situations (as shown in figure 4) indicates a good level of content validity.

As for the construct validity related to how well and precise the instrument was set to measure a certain linguistic construct, it is worth mentioning that DCT is a well-known instrument used widely in many speech act studies (Kasper, 2000; Jasim, 2017). It is also preferred to elicit politeness constructs because according to Tran (2005), it allows the researchers to include the social variables they desire to investigate. In this respect, the WDCT was solely set to elicit the structure and directness of suggestions and the MDCT was set to elicit politeness of suggestions. Generally, with regards to reliability within the testing of variables, the current study because it has enabled the researcher to identify gender effect (independent variable) on the production of the structural, 
directness, and politeness strategies (dependent variables) as it was revealed in the linguistic analysis part, then the WDCT and MDCT are two reliable instruments. In conclusion, the current DCTs were found reliable and valid to be replicated. So, they can also be used in other pertinent studies where the speech act of suggestion is targeted.

\section{Conclusion}

Since the results and discussions section was divided into three subsections (the linguistic analysis section, raters' response analysis section, and procedural issues section), so the conclusion was branched into three parts accordingly.

In terms of the linguistic analysis of the overall performance in the DCTs, the study has revealed that the female performed better in the WDCT than the male. From a broader perspective, this finding goes in line with findings by Edstrom (2004) in which the female performed better linguistic abilities than the male. As for the structure of suggestions, the statistical analysis revealed that gender exercised an effect where the female were found to produce relatively a higher number of strategies than the male. Regarding the directness of suggestions, the analysis uncovered that gender affects the use of directness strategies as the male were found to make a relatively higher number of direct suggestions than the female. On the other hand, the female were found more indirect in their suggestions. Such results of directness resemble others by Mulac, Bradac \& Gibbons (2001) and Nelson, Al Batal, \& El Bakary (2002). About politeness, the statistical analysis showed that gender has no effect on the choice of politeness strategies. With this no variance, the current results contradict Yousefvand's (2010) claim that the female are more aware of the concept of 'face' than the male. This result, however, confirms Ahangar \& Ali Akbari's (2007) claim that gender is an insignificant variable.

In terms of the raters' response, the analysis revealed that the four raters have positively rated the WDCT and MDCT situations which means that the face validity of the two tasks has been achieved. Other types of validity; content and construct validity have also been attained and thus the two DCTs are reliable and ready for use by relevant future studies.

Finally, in terms of the issues raised in the conduction of this study, no serious problems appeared and the two tasks can be confidently re-used. This confidence is supported by the good levels of validity and reliability which were discussed above.

\section{Acknowledgement}

This research paper was funded by Universiti Tun Hussein Onn Malaysia (UTHM) under TIER 1 grant (Vot. H193).

\section{References}

Abed, A. Q. (2011). Pragmatic transfer in Iraqi EFL learners' refusals. International Journal of English linguistics, $1(2), 166-185$.

Ahangar, A. A., \& Amou Ali Akbari, Sh. (2007). Linguistic Politeness in Persian: Requestive Speech Act Strategies Employed by Male and Female Persian Speakers. Paper Presented at Second International Conference on Iranian Linguistics.

Al-aadeli, N. M. (2014). Suggestion and advice in three selected plays. Journal of Educational and Practice, 5(4), 1425 .

AL-Khanaifsawy, A. N. (2014). An analytic study of the difficulties faced by Iraqi EFL learners in the use of disagreement (Master's thesis). University of Qadisiayh, Diwaniyah, Iraq.

Arani, S. S., \& Tehrani, N. S. (2013). The impact of age and sex on the refusal strategies used by Iranian EFL learners. International Journal of Applied Linguistics and English Literature, 2(4), 110-117.

Brown, P., \& Levinson, S. C. (1987). Politeness: Some universals in language usage (Vol. 4). Cambridge: Cambridge university press. 
Carr, N. T. (2011). Designing and analysing language tests: Oxford handbooks for language teachers. Oxford, UK: Oxford University Press.

Coates, J. (2015). Women, men and language: A sociolinguistic account of gender differences in language. London: Routledge.

Creswell, J. W. (2012). Educational research: Planning, conducting and evaluating quantitative and qualitative research. (4th ed.). Boston, MA: Pearson.

Devici, T. (2015). The complaint speech act set produced by university students speaking English as a foreign language. Literacy Information and Computer Education Journal (LICEJ) 4, 2161-2171.

Edstrom, A. (2004). The L2 as language of instruction: Teachers explore the competing tensions. In The Northeast Conference on the Teaching of Foreign Languages (Vol. 55, pp. 26-32).

Edstrom, A. (2008). Making suggestions while collaborating in L1 English: Common structures and strategies. Miscelánea, 51(5), 27-48.

Ehrlich, S., Meyerhoff, M., \& Holmes, J. (Eds.). (2017). The handbook of language, gender, and sexuality. John Wiley \& Sons.

Elham, A. (2017). An investigation of apology strategies employed by Iranian EFL learners. International Journal of Research Studies in Education, 6(3), 27-37.

Given, L. M. (2008). The SAGE encyclopedia of qualitative research methods (Vol. 10). Thousand Oaks, CA: SAGE Publications, Inc. DOI: 10.4135/9781412963909

Heaton, J. (1988). Writing English language tests: A practical guide for teachers of English as a second or foreign language. London: H. Charles and Co. Ltd.

Heidari, A., Rasekh, A. \& Simin, S. (2014). Speech act disagreement among young men in Iran. International Letters of Social and Humanistic Sciences (ILSHS), 37, 97-109.

Jasim, M. (2017). Refusals of requests and offers in Iraqi Arabic and British English (Doctoral Dissertation). The University of Manchester.

Jiang, X. (2006). Suggestions: What should ESL students know? System, 34, 36-54.

Kasper, G. (200o). Data Collection in Pragmatics Research. In Helen Spencer-Oatey (ed.), Culturally Speaking; managing Rapport Through Talk Across Cultures, pp. 316-341. London: Continuum.

Kassem, M. A. M. (2018). The effect of a suggested in-service teacher training program based on MALL applications on developing EFL students' vocabulary acquisition. Journal of Language Teaching and Research, 9(2), 250-260.

Keshani, K., \& Heidari-Shahreza, M. A. (2017). A comparative study of apology strategy use by Iranian and German EFL learners: gender differences in focus. Journal of Applied Linguistics and Language Research, 4, 199-212.

Lancaster, G. A., Dodd, S., \& Williamson, P. R. (2004). Design and analysis of pilot studies: recommendations for good practice. Journal of evaluation in clinical practice, 10(2), 307-312.

Lee, E. C., Whitehead, A. L., Jacques, R. M., \& Julious, S. A. (2014). The statistical interpretation of pilot trials: should significance thresholds be reconsidered? BMC medical research methodology, $14(1), 41$.

Leech, G. (2016). Principles of pragmatics. London: Routledge.

Li, S. E. (2010). Making suggestions: A contrastive study of young Hong Kong and Australian students. Journal of Pragmatics, 42(3), 598-616.

Martínez-flor, A. (2005). A theoretical review of the speech act of suggesting: Towards a taxonomy for its use in FLT. Revista Alicantina de Estudios Ingles, 18, 167-187.

Moradi, R. (2017). A review on gender linguistics studies. Language Art, 2(2), 55-68.

Mulac, A., Bradac, J. J., \& Gibbons, P. (2001). Empirical support for the gender-as-culture hypothesis: An intercultural analysis of male/female language differences. Human Communication Research, 27(1), $121-152$.

Myles, J. (2002). Second language writing and research: The writing process and error analysis in student texts. TESL-EJ, 6(2), 1-20.

Nelson, G. L., Al Batal, M., \& El Bakary, W. (2002). Directness vs. indirectness: Egyptian Arabic and US English communication style. International Journal of Intercultural Relations, 26(1), 39-57.

Neuendorf, K. A. (2016). The content analysis guidebook. Sage.

Petrey, S. (2016). Speech acts and literary theory. New York: Routledge.

Pishghadam, R., \& Sharafadini, M. (2011). A contrastive study into the realization of suggestion speech act. Canadian Social Science, 7(4), 230-239.

Sharqawi, M. A., \& Anthony, E. M. (2019a). Speech acts and their underlying strategies by EFL learners and nonlearners: A systematic literature review. Revista Amazonia Investiga, 8 (20), 486-502.

Sharqawi, M. A., \& Anthony, E. M. (2019b). Recognizing suggestions by Iraqi English as a foreign language learner: A politeness perspective. Proceedings of Innovative Teaching and Learning Research Day, 2019. 
Sharqawi, M. A., \& Anthony, E. M. (2019c). Analysing the speech act of disagreement produced by Iraqi EFL learners: A gender study. Humanities E Social Sciences Reviews 7 (2), 118-134.

Sharqawi, M. A. \& Anthony E. M. (2020a). Iraqi EFL learners' recognition of politeness in the speech act of suggestion. International Journal of Scientific \& Technology Research, 9 (4), 2180-2191.

Sharqawi, M. A., \& Anthony, E. M. (2020b). Making suggestions: A perspective of perspectives. Journal of Educational and Social Research, 10 (2), 191-204.

Taqim, A. (2016). Politeness in speech act of disagreement by English learners of Lampung University (Master's thesis). Lampung University. Bandar, Indonesia.

Tran, G. (2005). The nature and conditions of pragmatic and discourse transfer in cross-cultural interaction investigated through naturalized role-play (Doctoral dissertation). The University of Melbourne.

Yousefvand, Z. (2010). Study of Compliment Speech Act Realization Patterns Across Gender in Persian. Arizona Working Papers in SLA E Teaching, 17, 91-112.

Yuksel, D., \& Inan-Karagul, B. (2018). Research Methods for Studying L2 Listening. The TESOL Encyclopedia of English Language Teaching, (Vol.8). University of Chicago Press. 